\title{
Evaluation of Right Ventricular Dilatation by M-Mode Echocardiography
}

\author{
Ikuo Hashimoto ${ }^{1}$
}

Received: 12 April 2016/Accepted: 22 April 2016/Published online: 9 May 2016

(C) Springer Science+Business Media New York 2016

I read the letter to the editor from Schweintzger et al. and deeply appreciated their comments and suggestions. They encouraged us to promote the use of our index for screening children with right ventricular (RV) dilatation due to isolated atrial septal defect (ASD). As noted in our article, we already recognize some problems and limitations in our methods [1]. M-mode scanning of the heart is easy and time-saving. However, the M-mode method is still a onedimensional measurement and may not allow proper evaluation of the heart with a three-dimensional configuration. Errors of measurement may become large depending on the position of the M-mode line. To minimize these errors, we need to pay attention to both the M-mode line and body position. However, these relationships change with growth and maturation. Use of a large number of healthy children as a control is expected to provide optimal growth-related cutoff values to minimize these errors. Three-dimensional echocardiography does not require geometrical assumptions for volumetry and is an ideal method to analyze right ventricular volume and function, but it is time-consuming and requires after-processing [2]. This may be the greatest barrier to its implementation in a clinical setting. However, the dimensional change of the heart due to volume overload usually occurs radially, not longitudinally, probably because the heart is enclosed by the thorax, which limits the heart's longitudinal motion and enlargement $[3,4]$. Therefore, volume overload is mostly expressed as a radial

Response to Letter to the Editor 10.1007/s00246-016-1405-8.

Ikuo Hashimoto

i.hashimoto@icloud.com

1 Department of Pediatrics, Toyama City Hospital, 2-1 Hokubu Mach, Imaizumi, Toyama City, Toyama, Japan dimensional change, and we concluded that measurement of radial RV dimension by comparing the left ventricular $(\mathrm{LV})$ dimension is reasonable for evaluation of $\mathrm{RV}$ dilatation in children.

Measuring RV or right atrial area two-dimensionally will provide a more accurate means of diagnosing ASD [5]. However, the RVD/LVD ratio can be obtained by M-mode in a routine echocardiographic examination. We hope this will be a useful index for screening patients with ASD.

\section{Compliance with Ethical Standards}

Conflict of interest None.

\section{References}

1. Hashimoto I, Watanabe K, Ichida F (2016) Right to left ventricular diameter ratio $\geq 0.42$ is the warning flag for suspecting atrial septal defect in preschool children: age- and body surface area-related reference values determined by M-mode echocardiography. Pediatr Cardiol 37:704-713

2. Watanabe K, Hashimoto I, Ibuki K, Okabe M, Kaneda H, Ichida F (2015) Evaluation of right ventricular function using single-beat three-dimensional echocardiography in neonate. Pediatr Cardiol 36:918-924

3. Koestenberger M, Nagel B, Ravekes W, Everett AD, Stueger HP, Heinzl B, Sorantin E, Cvirn G, Gamillscheg A (2011) Tricuspid annular plane systolic excursion and right ventricular ejection fraction in pediatric and adolescent patients with tetralogy of Fallot, patients with atrial septal defect, and age-matched normal subjects. Clin Res Cardiol 100:67-75

4. Hashimoto I, Watanabe K (2014) Alternation of right ventricular contraction pattern in healthy children-shift from radial to longitudinal direction at approximately $15 \mathrm{~mm}$ of tricuspid annular plane systolic excursion. Circ J 78:1967-1973

5. Kelly NF, Walters DL, Hourigan LA, Burstow DJ, Scalia GM (2010) The relative atrial index (RAI) - a novel, simple, reliable, and robust transthoracic echocardiographic indicator of atrial defects. J Am Soc Echocardiogr 23:275-281 